\title{
Optimal operation strategy for subway HVAC system in transition seasons
}

\author{
Yue Zhang ${ }^{1}$, Xiaofeng $\mathrm{Li}^{1,{ }^{*}}$ Bin Wang ${ }^{2}$ Zheren Song ${ }^{2}$ \\ ${ }^{1}$ Department of Building Science, Tsinghua Unversity, Beijing, China \\ ${ }^{2}$ Wuxi Metro Group Co., Ltd, Wuxi, China
}

\begin{abstract}
This paper mainly studied the operation strategy for subway VAC system during transition seasons. Two modes including WF-AC (Whole Fresh air- Air Conditioning) mode and B/E-V (Back/Exhausted fan-Ventilation) mode were selected based on energy saving principle. In order to decide the optimal operation mode, the calculation method of "switching temperature" was proposed. The main influencing factors of the switching condition include indoor cooling load, COP of the chilled-water-system, temperature difference of the supply air, efficiency of fan and the resistance of air duct. Also, the transfer temperature diagram is provided based on proposed calculation method, which is suitable for engineering use. The aim of this study is to regulate the operation mode and to promote energy saving in subway station.
\end{abstract}

\section{Introduction}

China is undertaking fast development in urban railway transits. According to the statistics, by the end of 2017 , 34 cities have subway lines, the total mileage is 3883.6 $\mathrm{km}$. However, the energy consumption of subway becomes a big problem in the same time $[1,2]$. The significance of subway Heating Ventilation and AirConditioning (HVAC) system design and management is widely agreed.

Numerous researchers have pointed out that HVAC system takes about $30 \%$ to $50 \%$ of the total energy consumption [3-5]. Because of the poor operation strategy, the subway HVAC system shows great energy saving potentials. Thus, study on optimizing operation strategies in subway HVAC system is meaningful.

Different from other types of buildings, in subway stations, there is no heat gain from solar radiation, and the heat transfer from building envelope cannot be neglected. As a result, the cooling load in subway station mainly comes from two parts: one part is the inner heat sources (such as the heat release from passengers, lights, equipment, elevators. etc); the other part is caused by the air exchange between the subway station and outdoor space. Previous research pointed out the difference of above two parts: the former part is almost invariant during the year; the later part is changing from time to time with the airflow fluctuation [6-11].

For summer and winter, the operation modes are for sure: In summer, the fresh air should keep at the lowest level to minimize the cooling load. In winter, the outdoor air is cool enough, so natural ventilation is applied during winter season $[12,13]$. However, the operation modes is under debate in transition seasons. In order to fill this gap, the operation strategy for subway HVAC system during transition seasons was studied in this paper.

\section{Analysis on ventilation modes}

The HVAC system in subway is different from that in other buildings

Based on different ways of airflow organization, there are three options for ventilation modes, listed as following:

- Mode A. Supply fan-only ventilation,

- Mode B. Supply fan \& Back/Exhausted fancombined ventilation

- Mode C. Back/Exhausted fan-only ventilation.

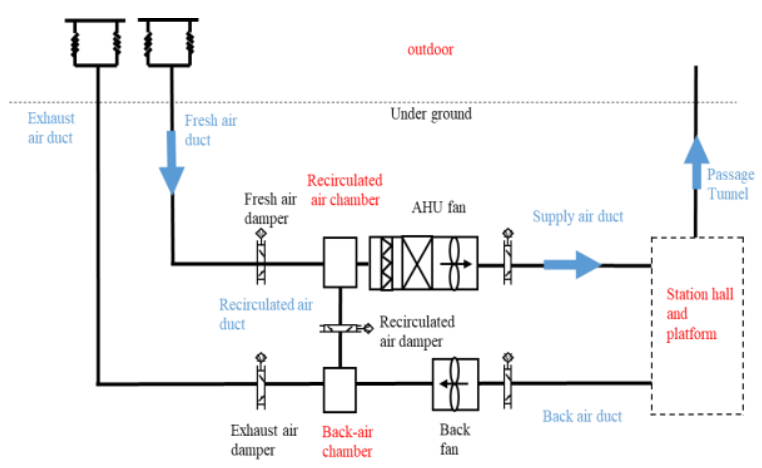

Fig. 1 Mode A. Supply fan-only ventilation

\footnotetext{
* Corresponding author: $\underline{x f l i @ \text { tsinghua.edu.cn }}$
} 
The ventilation Mode A is to use only one fan-supply fan. Fresh outdoor air was introduced into the AHU through fresh air duct, then been delivered to the station hall and platform through supply air duct. Under this condition, the pressure of station hall and platform is positive. Therefore, there is blowing feelings for passengers entering the station hall. In cold days, they mainly feel warm indoor air, which is regarded as moderate thermal comfort level.

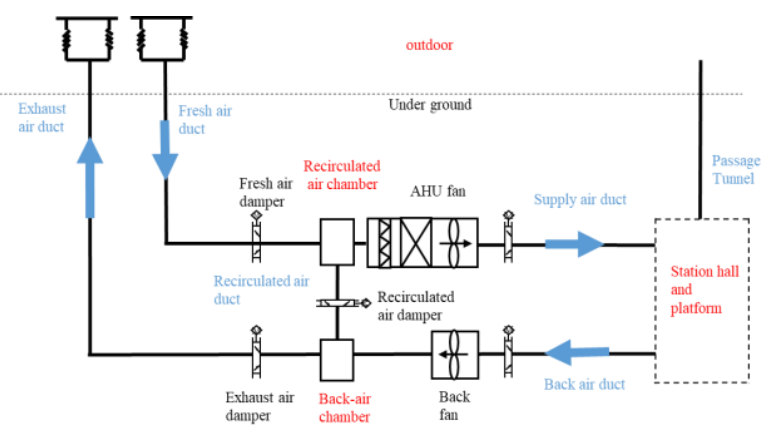

Fig. 2 Mode B. Supply fan \& Back/Exhausted fan-combined ventilation.

The ventilation Mode B is to use two fans-both supply fan and Back/Exhaust fan. When using this mode, the fresh outdoor air comes through fresh air duct, then through supply air duct to the station hall and platform. A part of the indoor air goes back to the back/exhausted air duct, and then enters outdoor environment. Because two fans are used in the mode, there is no doubt that the energy consumption is almost twice of other two modes. However, due to the operation of two fans, the pressure of station hall and platform is almost zero. So there is no strong blowing feelings at the entrance. Depending on this, ventilation mode B achieves the highest thermal comfort among the three modes.

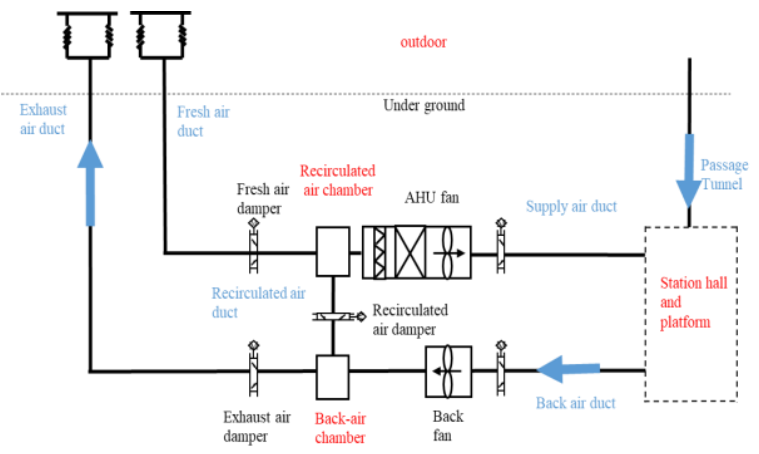

Fig. 3 Mode C. Back/Exhausted fan-only ventilation

The ventilation Mode $\mathrm{C}$ is to use only one fanback/exhaust fan. Because the resistance of back/exhaust air duct is smaller than that in supply air duct, the ventilation Mode $\mathrm{C}$ achieves the best energy saving performance. In this mode, a part of indoor air goes through the back/exhaust air duct, then comes to the outdoor space through exhaust air duct. In this situation, the pressure of the station hall and platform is negative, so when passengers exit, they feels cold wind blowing, which results in uncomfortableness.

The detailed comparison in respect of both energy consumption and thermal comfort listed in Table 1

Table 1. Energy consumption and thermal comfort comparison of three ventilation modes.

\begin{tabular}{|c|c|c|}
\hline $\begin{array}{c}\text { Ventilation } \\
\text { mode }\end{array}$ & $\begin{array}{c}\text { Energy } \\
\text { consumption }\end{array}$ & $\begin{array}{c}\text { Thermal } \\
\text { comfort }\end{array}$ \\
\hline A & Moderate & Moderate \\
\hline B & High & High \\
\hline C & Low & Low \\
\hline
\end{tabular}

In order to figure out which is the best ventilation mode in Air Conditioning season and non-Air Conditioning seasons, respectively, the energy consumption, thermal comfort features of the three modes should be considered in the same time.

In Air Conditioning season, chillers is needed. The Air Handling Unit (AHU) is located in the supply air duct, so the supply fan is needed during Air-Conditioning season. As a result, there are two options in AirConditioning season: Mode A and B.

In non-Air Conditioning seasons, either Supply fan or Back/Exhausted fan is available to deliver cool outdoor air to the station hall and platform. Thus, there are three options in total for non-Air Conditioning seasons: Mode $\mathrm{A}, \mathrm{B}$ and $\mathrm{C}$.

First of all, due to the differences in the resistance of air duct, the energy consumption is different among 3 modes. Moreover, the thermal comforts are different because of the distinction on airflow organization.

The mode $\mathrm{C}$ and $\mathrm{A}$ achieve relatively low thermal comfort because of the blowing feeling in the entrances of the subway station, but it acceptable for passengers who only spend several minutes entering the subway station.

Therefore, according to the energy saving principle, ventilation Mode A is adopted in Air Conditioning seasons, Mode $\mathrm{C}$ is applied in non-Air Conditioning seasons within transition seasons. To be more specific, during transition seasons, the enthalpy of outdoor air is lower than that of the indoor air, so the supply air is composed of fresh air when chiller is operating.

In summary, Whole Fresh air- Air Conditioning (WFAC) mode and Back/Exhausted fan-Ventilation (B/E-V) mode were selected in Air Conditioning time and nonAir Conditioning time, respectively during transition season. 


\section{Analysis on switching condition}

In this section, the switching condition between WF-AC mode and $\mathrm{B} / \mathrm{E}-\mathrm{V}$ mode was analysis by theoretical approach. The method was applied in case study and some general cases.

\subsection{Theoretical analysis}

In $\mathrm{B} / \mathrm{E}-\mathrm{V}$ mode, there is no energy consumption from chilled-water system, however the energy consumption from the fan is greater than that in WF-AC mode. Therefore, quantitative analysis is needed in determining the optimal operation mode during transition season.

Firstly, we define the outdoor air and supply air temperature difference as $\Delta \mathrm{T}$, the indoor air and supply air temperature difference as $\Delta \mathrm{T}_{0}$, which shows in Equation (1).

Equation (2) shows the two components of energy consumption in WF-AC mode $\left(\mathrm{P}_{\mathrm{AC}}\right)$ : energy consumption from chilled water system $\mathrm{P}_{\text {chill }}$ and energy consumption from supply fan $\left(\mathrm{P}_{\text {supply fan }}\right)$. For the first part, we use indoor cooling load $Q_{\text {in }}$ and the system coefficient of performance $\mathrm{COP}_{\text {sys }}$ to calculate $\mathrm{P}_{\text {chill }}$. For the second part, we use the resistance of air duct, air volume (from cooling load and temperature difference) and fan efficiency $\eta_{\text {supply }}$ to calculate $\mathrm{P}_{\text {supply fan }}$.

Equation (3) shows the only component of energy consumption in $\mathrm{B} / \mathrm{E}-\mathrm{V}$ mode: energy consumption from

Back/Exhaust fan $\mathrm{R}_{\text {back }} / \mathrm{ex}$ fan . We use the resistance of air duct, air volume and fan efficiency to

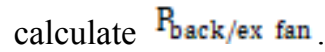

$$
\begin{aligned}
& \Delta T=T_{\text {outdoor }}-T_{\text {supply }}, \quad \Delta T_{0}=T_{\text {in }}-T_{\text {supply }} \\
& P_{A C}=P_{\text {caill }}+P_{\text {supply fan }}=\frac{Q_{\text {in }}}{\operatorname{CoP}_{\text {sys }}} \times \frac{\Delta T}{\Delta T_{0}}+\frac{S_{\text {supply }}}{\eta_{\text {supply } \times\left(\rho C_{p}\right)^{3}}} \times \frac{Q_{\text {in }}{ }^{3}}{\Delta T_{0}^{3}} \\
& P_{\text {Vent }}=P_{\text {back/ex fan }}=\frac{S_{\text {back } / e x}}{\eta_{\text {back } / e x} \times\left(\rho C_{p}\right)^{3}} \times \frac{Q_{\text {in }}{ }^{3}}{\left(\Delta T-\Delta T_{0}\right)^{3}}
\end{aligned}
$$

When the energy consumption of WF-AC mode and $\mathrm{B} / \mathrm{E}-\mathrm{V}$ mode equals to each other, there comes to the switching condition, which refers to the switching outdoor temperature in this research. If the outdoor air temperature is lower than the switching temperature, $\mathrm{B} / \mathrm{E}-\mathrm{V}$ mode is more energy-efficient, when the outdoor air temperature is higher than the switching temperature, WF-AC mode is a better option. From the principle shown in Equation (4), the simplified implicit equation and the details of coefficients $\mathrm{a}, \mathrm{b}$ and $\mathrm{c}$ are shown in Equation (5).

$$
P_{\text {AC }}=P_{\text {Vent }}
$$

$$
\begin{aligned}
& a \times\left(\Delta T-\Delta T_{0}\right)^{4}+b \times\left(\Delta T-\Delta T_{0}\right)^{3}+c=0 \\
& \text { where, } a=\frac{Q_{i n}}{\operatorname{COP}_{\text {sys }} \Delta T_{0}}, b=\frac{S_{\text {supply }} Q_{i n}{ }^{3}}{\eta_{\text {supply }}\left(\rho C_{p} \Delta T_{0}\right)^{3}}+\frac{Q_{i n}}{\operatorname{COP}_{\text {sys }}}, c= \\
& \frac{S_{\text {back } / e x} Q_{i n}{ }^{3}}{\eta_{\text {back } / e x}\left(\rho C_{p}\right)^{3}}
\end{aligned}
$$

Based on the above analysis, we can obtain the switching temperature using Equation (5).

Equation (5) is an implicit equation, so the value of indoor-outdoor air temperature difference $\Delta \mathrm{T}$ depends on the coefficients $\mathrm{a}, \mathrm{b}$ and $\mathrm{c}$, and also the setting value of temperature difference between indoor air and supply air. With this calculation method, we can eausily obtain the switching temperature, which is defined as the outdoor air temperature when WF-AC mode and $\mathrm{B} / \mathrm{E}-\mathrm{V}$ mode consume the same amount of energy.

The expression of coefficients $a, b$ and c shows the influencing factors of the switching temperature include Indoor cooling load $\left(\mathrm{Q}_{\text {in }}\right)$, coefficient of chilled water system $\left({ }^{{ }^{C O P}}\right.$ sys $)$, temperature difference of supply air and indoor air $\left(\Delta \mathrm{T}_{0}\right)$, efficiency of fans ( $\eta_{\text {supplys }} \eta_{\text {back } / e x}$ ) and the resistances of air ducts ( $\left.\mathrm{S}_{\text {supplys }} \mathrm{S}_{\text {back/ex }}\right)$.

\subsection{Case study}

In order to have concrete understanding of the switching temperature, case study was introduced in this chapter.

We select a typical subway station. The indoor cooling load includes load from passengers, lights, and other equipment, the value is from field investigation.

The supply air temperature is from design data, which is $18^{\circ} \mathrm{C}$ in most cases in subway stations of China.

The indoor air temperature is set at a constant level $28^{\circ} \mathrm{C}$, which equals to the setting point of indoor air temperature in summer. We also use $28^{\circ} \mathrm{C}$ as the the controlled indoor air temperature concerning both energy consumption and thermal comfort of passengers. The guidelines for appropriate indoor temperature during transition seasons are two indictors, Relative Warmth Index (RWI) \& Heat Deficit Rate (HDR) according to the Subway Environment Design Handbook provided by US Department of Transportation.

The coefficient of performance (COP) for the chilled water system was obtained from field measurements. Based on the measured data, the COP of the chillered water system only shows some slight changes, so the constant value $(\mathrm{COP}=4)$ is applied in the analysis of case study.

All of the details of above parameters listed in Table 2 as following. 
Table 2. Parameters in case study

\begin{tabular}{|c|c|c|}
\hline Parameter & Value & Unit \\
\hline $\mathrm{Q}_{\text {in }}$ & 100 & $\mathrm{~kW}$ \\
\hline $\mathrm{T}_{\text {supply }}$ & 18 & ${ }^{\circ} \mathrm{C}$ \\
\hline $\mathrm{T}_{\text {in }}$ & 28 & ${ }^{\circ} \mathrm{C}$ \\
\hline $\mathrm{S}_{\text {supply }}$ & 2.16 & $\mathrm{~Pa} /\left(\mathrm{m}^{3} / \mathrm{s}\right)^{2}$ \\
\hline S back/ex & 1.44 & $\mathrm{~Pa} /\left(\mathrm{m}^{3} / \mathrm{s}\right)^{2}$ \\
\hline 1)upply & $70 \%$ & I \\
\hline Mback/ex & $70 \%$ & I \\
\hline $\mathrm{COP}_{\text {sys }}$ & 4 & I \\
\hline
\end{tabular}

After this input parameters, we are able to calculate the energy consumption of both WF-AC mode and B/E-V mode.

According to Equation (2) and Equation (3), we can get the energy consumption in different outdoor temperatures of WF-AC mode and B/E-V mode, respectively. The calculated results show in Figure 1.

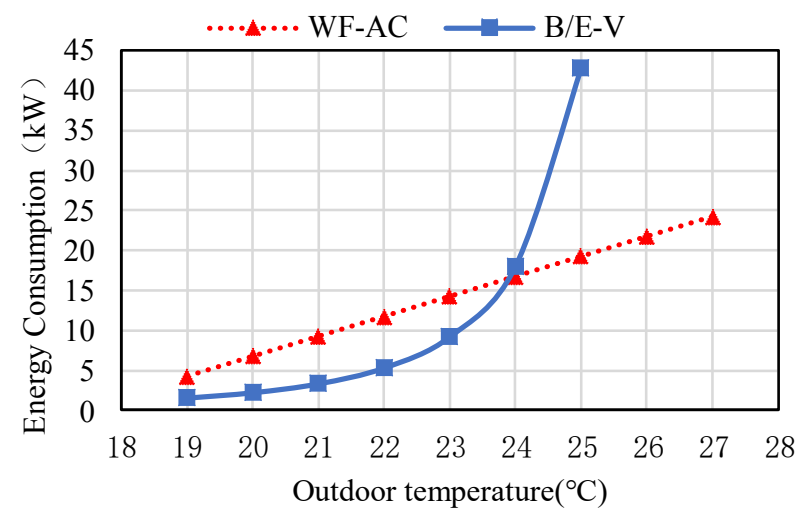

Fig. 4. Energy consumption of WF-AC mode and B/E-V mode in different outdoor temperatures.

We can find out the pattern of energy consumption for both WF-AC mode and B/E-V mode.

There are things in common: with the increasing of outdoor temperature, the energy consumption of the two mode both increase. But the increasing pattern differs. In WF-AC mode, there shows linear relationship between the total energy consumption and the outdoor temperature. In B/E-V mode, there shows cubic increasing pattern between the total energy consumption and the outdoor temperature. To be more specific, the energy consumption of fans and its air volume shows cubic relationship when frequency conversion technology is applied. The two curves cross at one point, which is switching temperature $\left(24^{\circ} \mathrm{C}\right)$ in this case.

Therefore, according to energy saving principle, when the outdoor temperature is lower than the switching temperature $\left(24^{\circ} \mathrm{C}\right), \mathrm{B} / \mathrm{E}-\mathrm{V}$ mode should be applied; when the outdoor temperature is higher than the switching temperature $\left(24^{\circ} \mathrm{C}\right)$, WF-AC mode should be applied.

From this case study, we can clearly decide which mode is more energy-efficient under different outdoor temperatures. In a word, switching temperature is a good indictor to determine the optimal operation mode.

\subsection{General study}

According to Equation (5), we can calculate some general cases.

In reality, the indoor cooling load can be variable, depending on the passenger number, heat release of lights and other equipment, so the range is from $50 \mathrm{~kW}$ to $300 \mathrm{~kW}$. The efficiency of fans also differs a lot, depending on the operation years and qualities of different products, so the fan efficiency varies from $50 \%$ to $70 \%$. In the same way, the coefficient of performance for chilled water system differs by means of different chillers, different situations of water pumps. In the general study, the COP varies from 3 to 5 .

Compared to indoor cooling load and coefficient of the equipment, other parameters keep at an almost constant level, so the temperature of supply air and indoor air, the resistance of supply air duct and back/exhausted air duct are the same as those in case study.

The specific values of each parameter shown in Table 3.

Table 3. Parameters in general study

\begin{tabular}{|c|c|c|}
\hline Parameter & Value & Unit \\
\hline$Q_{\text {in }}$ & {$[50,300]$} & $\mathrm{kW}$ \\
\hline $\mathrm{T}_{\text {supply }}$ & 18 & ${ }^{\circ} \mathrm{C}$ \\
\hline $\mathrm{T}_{\text {in }}$ & 28 & ${ }^{\circ} \mathrm{C}$ \\
\hline $\mathrm{S}_{\text {supply }}$ & 2.16 & $\mathrm{~Pa} /\left(\mathrm{m}^{3} / \mathrm{s}\right)^{2}$ \\
\hline$S_{\text {backjex }}$ & 1.44 & $\mathrm{~Pa} /\left(\mathrm{m}^{3} / \mathrm{s}\right)^{2}$ \\
\hline$\eta_{\text {supply }}$ & {$[50 \%, 70 \%]$} & I \\
\hline Mback/ess & {$[50 \%, 70 \%]$} & I \\
\hline $\mathrm{COP}_{\text {gys }}$ & {$[3,5]$} & I \\
\hline
\end{tabular}

Based on the parameters listed in Table 3, the switching temperatures under different conditions plotted in Figure 5 to Figure 7. 


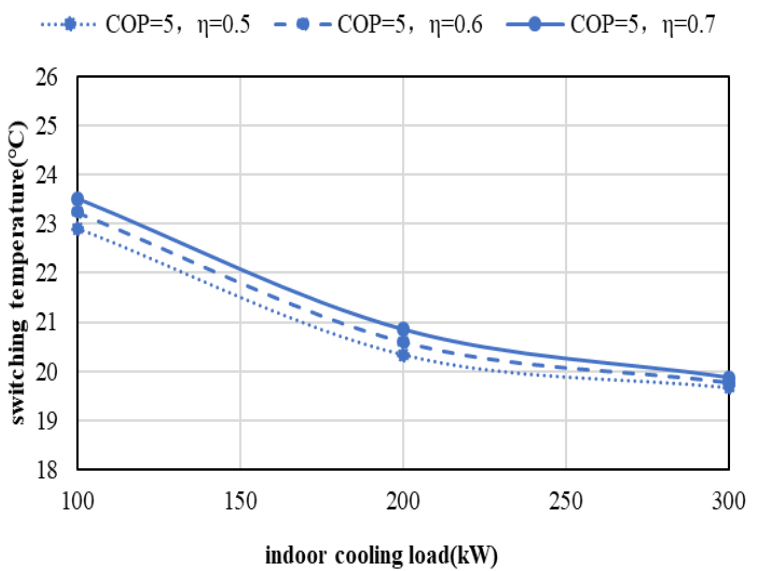

Fig. 5. Switching temperature in different indoor cooling loads and fan efficiencies when COP is 5 .

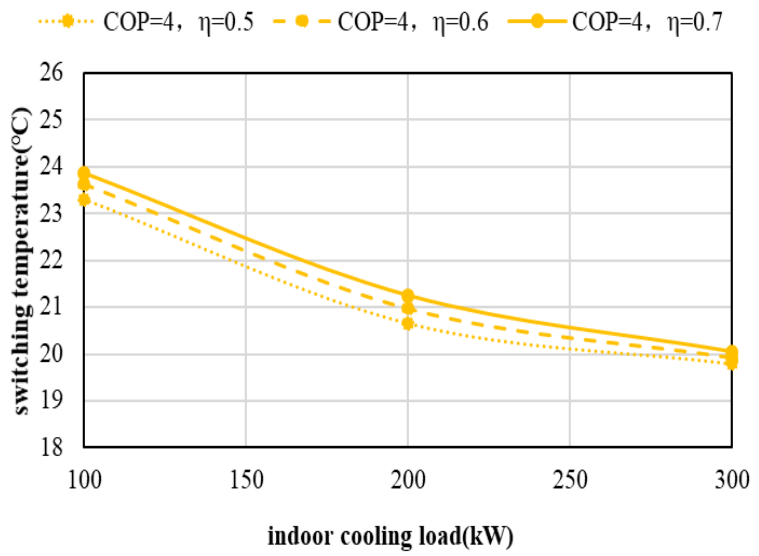

Fig. 6. Switching temperature in different indoor cooling loads and fan efficiencies when COP is 4.

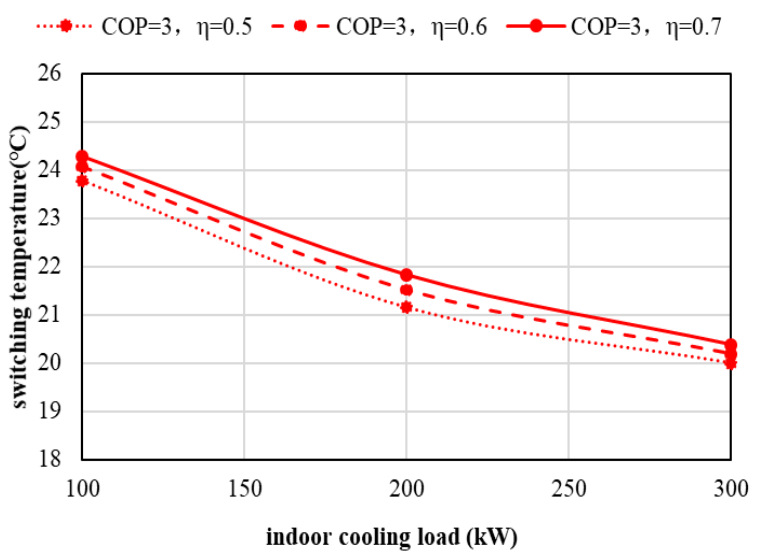

Fig. 7. Switching temperature in different indoor cooling loads and fan efficiencies when $\mathrm{COP}$ is 3 .
Thus, we can use Figure 5 to Figure 7 to find out the switching temperature under different conditions. Then determining which operation mode is more suitable (between WF-AC and B/E-V) in different outdoor temperature with different fan and chiller's performance.

\section{Conclusion}

This paper mainly studied the operation strategy for subway HVAC system during transition seasons. Two modes including WF-AC (Whole Fresh air- Air Conditioning) mode and B/E-V (Back/Exhausted fanVentilation) mode are selected based on energy saving principle.

Firstly, the indictor "switching temperature" and its theoretical calculation method were proposed in this research. If the outdoor temperature is lower than that switching temperature, Back/Exhausted-Ventilation mode should be applied to achieve lower energy consumption, and vice versa.

Moreover, case study was introduced to show the principle in real situation. In order to generalize the operation strategy, some general study was also conducted. As a result, a line graph that covers most cases was given for engineering use. This study is meaningful for energy saving in subway stations.

\section{References}

1. M. Casals, M. Gangolells, N. Forcada et al. Energy and Building. 78, 89-97 (2014)

2. J. Ahn, S. Cho, D.Chung. Applied Energy. 179, 488-496 (2016)

3. B. Guan, X. Liu, T. Zhang et al. Sustainable Cities and Society. 43, 451-461 (2018)

4. Y. Wang, H Feng, X. Xi. Energy for Sustainable Development. 39, 1-12 (2017)

5. A. González-Gil, R. Palacin, P. Batty et al. Energy Conversion and Management. 80, 509-524 (2014)

6. A. Khayrullina, B. Blocken, W. Janssen et al. Journal of Wind Engineering and Industrial Aerodynamics. 139, 100-110 (2015)

7. Y. Wang, X. Li. Building and Environment. 125, 556-564 (2017)

8. Y. Wang, X. Li. Sustainable Cities and Society. 38, 98-108 (2018)

9. Y. Zhang, X. Li. Sustainable Cities and Society. 42, 434-443 (2018)

10. J. Kim, K. Kim. Tunnelling and Underground Space Technology. 22(2), 166-172 (2007)

11. Y. HUANG, W. GAO, C. KIM. Journal of Hydrodynamics, 22(2), 164-172 (2010)

12. S. Hu, J. Lee. Energy Conversion and Management. 45(5), 639-650 (2004)

13. H. Zhang, T. Cui, M. Liu et al. Building and Environment, 126, 68-81 (2017) 